\title{
An integrated magnetic sensor : the silicon on sapphire Schottky magnetodiode (*)
}

\author{
S. Cristoloveanu, A. Mohaghegh \\ E.N.S.E.R., 23, Av. des Martyrs, 38041 Grenoble Cedex, France \\ and J. de Pontcharra \\ LETI/MEA, B.P. 85X, 38041 Grenoble Cedex, France
}

(Reçu le 20 décembre 1979, accepté le 10 mars 1980)

\begin{abstract}
Résumé. - Le magnétodiode à sonde Schottky est la combinaison de deux phénomènes : l'effet magnétodiode dans des structures doubles-injectantes $\mathrm{P}^{+} \mathrm{NN}^{+}$et l'effet de la modulation de la densité des porteurs sur le courant inverse de la diode Schottky. Nos dispositifs, réalisés en technologie silicium sur isolant, ont des sensibilités d'environ $10 \mathrm{~V} / \mathrm{T}$. Nous étudions l'influence des paramètres géométriques, du taux d'injection et du dopage en vue d'optimiser la sensibilité du capteur.
\end{abstract}

\begin{abstract}
The Schottky magnetodiode is the combination of two basic phenomena : the magnetodiode effect in double-injecting $\mathrm{P}^{+} \mathrm{NN}^{+}$structures and the effect of the carrier density modulation on the Schottky reverse current. Our devices, realized in SOS technology, denote magnetosensitivities of about $10 \mathrm{~V} / \mathrm{T}$. We investigate the influence of the geometrical parameters, injection rate and doping level in order to improve the device sensitivity.
\end{abstract}

1. Introduction. - Integrated magnetic sensors are subject to considerable theoretical interest and experimental work. This is due to their high number of applications :

- Magnetic detectors (control, metering and contactless switching, detection of angle, position, pressure etc...);

- Vehicles for the semiconductor characterization (bulk and surface recombination parameters, nonuniform processes, etc... [1]).

Conventional magnetosensitive devices based on the Hall effect are not easily compatible with the integrated circuits technology : the Hall field is important in semiconductors with high carrier mobilities (InSb, InAs, ...), but not in silicon [2]. To compensate this low sensitivity large dimensions $\left(20 \mathrm{~mm}^{2}\right.$ [3] would be needed, leading to high power dissipations and reproducibility problems.

The so called magnetodiodes (MD), already realized on bulk silicon using planar techniques [4] or on Silicon on Sapphire (SOS) [5], [6] according to the integrated circuits technology, are a much better solution from the point of view of sensitivity and

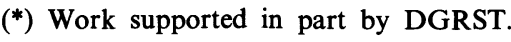

dimensions. In particular it has been shown that SOS meets naturally the MD requirements : strongly different recombination rates at $\mathrm{Si}-\mathrm{Al}_{2} \mathrm{O}_{3}$ and $\mathrm{Si}-\mathrm{SiO}_{2}$ interfaces, film thickness of the order of the ambipolar diffusion length $\left(L_{\mathrm{a}} \simeq 1 \mu\right)$.

In this communication we present a new kind of MD : the SOS Schottky magnetodiode (SOS-SMD) [7].

This device combines effects and sensitivities of usual double-injecting $M D$ (perturbation of carrier density by crossed electric and magnetic fields) and of Schottky diodes (influence of carrier excess or lack on the reverse saturation current).

2. Qualitative model. - In crossed electric $E_{x}$ and magnetic $B_{z}$ fields, the electron-hole pairs injected by the end contacts $\mathrm{P}^{+} \mathrm{N}$ and $\mathrm{NN}^{+}$are submitted to Lorentzian deflections (Fig. 1a). This leads to a transverse carrier gradient $n(y)$ and consequently to the modification of the mean carrier density. The effect which creates a transverse carrier gradient is usually called magnetodiode effect (MD) in injecting structures $[1,8,11]$ and magnetoconcentration effect (MC) in non injecting structures $[9,10]$.

Moreover an important carrier accumulation or depletion for $B_{z}$ or $-B_{z}$ is obtained in the proximity of the low recombining $\mathrm{Si}_{-} \mathrm{SiO}_{2}$ interface. This is 


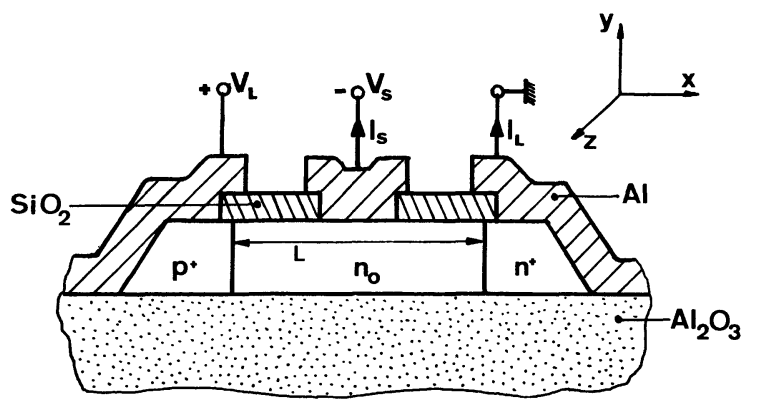

Fig. 1a. - SOS-SMD structure.

the basic mechanism responsible for the high sensitivity of SOS-SMD : the carrier density variation at the limit between the Schottky space charge region and the neutral substrate directly modulates the Schottky reverse current.

In near intrinsic semiconductors the pure MC effect is sufficient for the Schottky diode monitoring; thus a MC device with Schottky probe has been previously realized on germanium [12].

In the more general case of doped semiconductors the MC effect is attenuated. The originality of SOSSMD comes from their injecting contacts, which allow the generation of a high density electron-hole plasma. So this new and more complex device belongs to magnetodiodes family.

3. Experiments. $-\mathrm{P}^{+} \mathrm{NN}^{+}$structures using standard MOS aluminium gate technology were processed on $0.65 \mu$ thick $\langle 100\rangle$ SOS substrates. The diode base dopings $n_{0}$ are obtained by $80 \mathrm{keV}$ phosphorus ion implantation with $5 \times 10^{11}$ to $5 \times 10^{13} \mathrm{~cm}^{-2}$ dose. The base length values are $L=20,30$ and $50 \mu$ and the diode widths are $W=50,100$ and $200 \mu$.

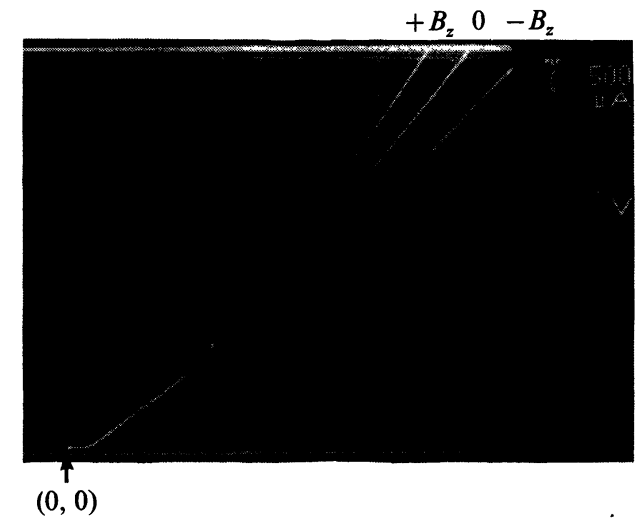

Fig. 1b. - Longitudinal forward characteristics $I(V)$ of a $5 \times 10^{15} \mathrm{~cm}^{-3}$ doped diode : length $20 \mu$, width $200 \mu$. Magnetic induction : $-1 \mathrm{~T}, 0,+1 \mathrm{~T}$.
The longitudinal diode works under forward bias, figure $1 b$. The Schottky diode located on the top of the base is reverse-biased, figure $1 a$. The reverse characteristic of the Schottky diode is largely modified by the longitudinal current injection $I_{\mathrm{L}}$ and by the magnetic induction, figure $1 c$.

$(0,0)$

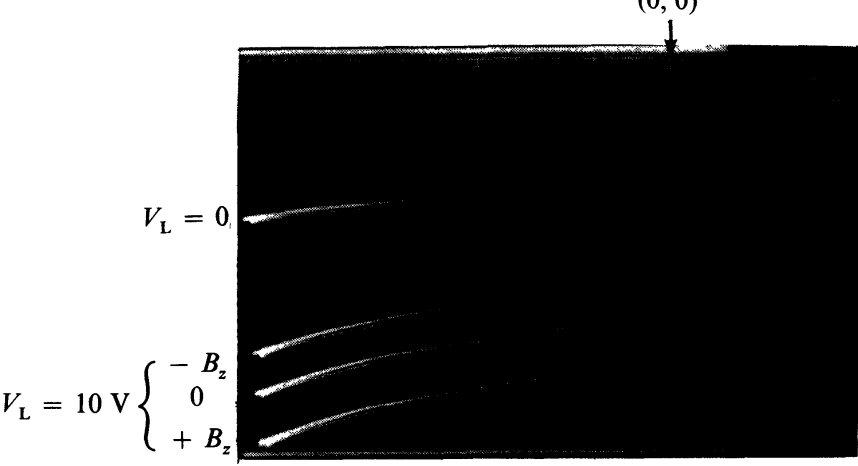

Fig. 1c. $-I(V)$ Schottky reverse characteristic. Schottky diode area : $6 \times 40 \mu^{2}$. Forward bias of the longitudinal diode $V_{\mathrm{L}}=10 \mathrm{~V}$. Magnetic induction : $+1 \mathrm{~T}, 0,-1 \mathrm{~T}$.

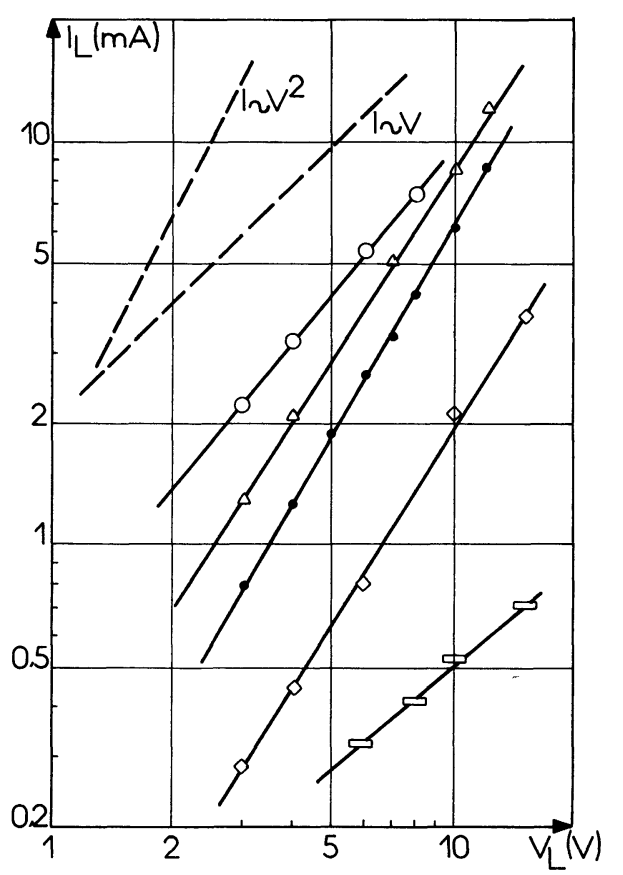

Fig. 2. - Longitudinal $I(V)$ characteristics for different magnetodiodes : $-\mathrm{O}-\mathrm{O}-\left(n_{0}=2 \times 10^{17} \mathrm{~cm}^{-3} ; L=20 \mu ; W=50 \mu\right)$; $-\triangle-\triangle-\triangle-\left(5 \times 10^{15} ; 20 ; 200\right) ;-\left(2 \times 10^{15} ; 10 ; 50\right)$; $-\diamond-\diamond-\left(5 \times 10^{15} ; 20 ; 50\right) ;-\square-\square-\square-\left(2 \times 10^{15} ; 50 ; 200\right)$.

In the next table, sensitivities of SOS-SMD and longitudinal MD are compared for the same injection level, $I_{\mathrm{L}}=5 \mathrm{~mA}$ :

Table I. - Compared sensitivities of longitudinal magnetodiode (MD) and associated Schottky magnetodiode (SMD). Working points are indicated in parentesis.
$\frac{\Delta V}{\Delta B}\left(\mathrm{~V} \cdot \mathrm{T}^{-1}\right)$
$\frac{\Delta I}{I \Delta B}\left(\mathrm{~T}^{-1}\right)$
$\frac{\Delta R}{R \Delta B}\left(\mathrm{~T}^{-1}\right)$
MD
$1\left(I_{\mathrm{L}}=5 \mathrm{~mA}\right)$
$0.16\left(V_{\mathrm{L}}=10 \mathrm{~V}\right)$
$0.1\left(R_{\mathrm{L}}=2 \times 10^{3} \Omega\right)$
SMD
$10\left(I_{\mathrm{S}}=37 \mu \mathrm{A}\right)$
$0.17\left(V_{\mathrm{S}}=4 \mathrm{~V}\right)$
$1.5\left(R_{\mathrm{S}}=2 \times 10^{5} \Omega\right)$ 
It is found that the SOS-SMD is especially sensitive if the working point of the $\mathrm{P}^{+} \mathrm{NN}^{+}$diode corresponds to a double injection characteristic, at least the semiconductor regime with $I_{\mathrm{L}} \sim n_{0} \frac{V_{\mathrm{L}}^{2}}{L^{3}}$.

For long diodes or for high base doping levels, the semiconductor regime is not easily reached, figure 2 .

We studied also several diodes widths but this parameter does not influence the sensitivity : the same current density gives the same magnetosensitivity. The narrower devices are preferable from the point of view of power dissipation.

4. Conclusion. - The optimization of the SOSSMD depends on the longitudinal double injection improvement. This can be done by lower doping levels or shorter bases. But for doping levels below $10^{15} \mathrm{~cm}^{-3}$, severe reproducibility problems appear due to the $\mathrm{Si}-\mathrm{Al}_{2} \mathrm{O}_{3}$ interface states density. Moreover the base length must be $L>L_{\mathrm{a}}$ (for SOS $L_{\mathrm{a}}$ is about $1 \mu)$. The best $L$ seems to be from 10 to $20 \mu$.
The transformation of the intimate metal-semiconductor Schottky contact into a MIS structure by adjonction of a $2 \mathrm{~nm}$ oxide layer should increase the present sensitivity [13].

The magnetosensitivity exhibited by SOS-SMD is one or two orders of magnitude higher than for silicon Hall sensors. The signal linearity depends on the electrical working points both of SMD and MD and on the magnetic induction range. The low reverse bias level involves relatively reduced noise ; nevertheless the most important limitation, in connection with the detection of very small magnetic fields, seems to be the sensitiveness variation with the temperature. Systematic analysis of noise-frequency dependence and thermal fluctuations will be performed.

Finally, the micronic dimensions will allow easy integration of several SOS-SMD associated with well adapted MOS amplifier units.

Acknowledgments. - Drs. J. Borel, A. Chovet, P. Jeuch, G. Kamarinos are especially acknowledged for very useful comments on this work.

\section{References}

[1] Cristoloveanu, S., Chovet, A., Kamarinos, G., SolidState Electron. 21 (1978) 1563.

[2] WeIss, H., Structure and application of galvanomagnetic devices (Pergamon Press) 1969.

[3] Sprague Electronic Company, Engineering bul. 27404.11.

[4] Karakushan, E. I., Ponomarev, Y. G., Stafeev, V. I., Sov. Phys. Semicond. 13 n $^{\circ} 2$ (1979) 171.

[5] Kamarinos, G., Viktorovitch, P., Cristoloveanu, S., Borel, J., Staderin, R., I.E.D.M., Washington, Techn. Digest 114A (1977).

[6] Lilienkamp, P., Pfleiderer, H., Phys. Status Solidi (a) 43 (1977) 479.
[7] Bern, J. P., Chretien, J., Kamarinos, G., Pellet, M. VIKTOROVITCH, P., Patent $\mathrm{n}^{\circ}$ 77.39.159 (1977), realized by LETI/MEA, Grenoble.

[8] Pfleiderer, H., Solid-State Electron. 15 (1972) 335.

[9] Madelung, O., Tewardt, L., WelKer, H., Z. Natursforsch. 10a (1955) 476.

[10] Chovet, A., Kamarinos, G., Revue Phys. Appl. 6 (1971) 345.

[11] Pfleiderer, H., Phys. Status Solidi (a) 53 (1979) 187.

[12] Chretien, J., Kamarinos, G., Viktorovitch, P., Revue Phys. Appl. 12 (1977) 1699.

[13] Kamarinos, G., Pananakakis, G., Viktorovitch, P., Inst. Phys. Conf. Ser. $\mathrm{n}^{\circ}$ 50, chapter 3, to be published. 